1. Goldstein, D.B. Nature Genet. 29, 109-111 (2001).

2. Crick, F.H.C. Symp. Soc. Exp. Biol. 12, 138-163 (1957).

3. Jacob, F. Science 196, 1161-1166 (1977)

4. Judson, H.F. The Eighth Day of Creation 608 (Cold Spring Harbor Laboratory Press, Cold Spring Harbor, 1996). dependent on the protein-protein interactions that underlie alternative splicing, post-translational modification, gene silencing and epigenetic regulation, in addition to a whole host of environmental factors. Commoner seems to be arguing that geneticists have documented this complexity, but have not taken it to heart: "Divergent evidence is duly reported and, often enough, generates intense research, but its clash with the governing theory is almost never noted."

But what can this mean? That geneticists really think their subject can be reduced to the simplified shorthand they sometimes employ in public pronouncements? Surely not. That because the Human Genome Project has been subject to hype, there is no there there? Can it really have escaped Commoner's notice that the availability of a complete genome sequence, or even a partial one, is a great boon to the study of the complexity he insists is being swept under the rug?

Lest this be taken as a dismissal of all criticism, it is important to add that the relationship between genetics and biotechnology deserves more rigorous review (see page 355). Finally, the Harper's article should prompt us to heed the words of Horace Freeland Judson": "Less is not more....Oversimplification creates confusion that no reader can comprehend: fuller explanation will bring enlightenment. More can simplify." Bearing this in mind, geneticists need to do a better job of conveying the fact that biology is complicated, and that the human genome sequence has not made understanding it easy_-just a little less hard.

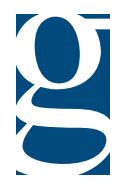

\title{
Ten years on
}

It is ten years since the launch of Nature Genetics. As explained in the inaugural issue, the journal set out to publish studies that explore the link between genome structure and human disease, the genetics of other organisms, reports on new technologies, and the application of research to genetic therapies. It was also argued that genetic research could provide insights into general biology and ventured that genetics might serve to answer some of the grander questions of biology. It was recognized that genetic research raises important social issues, the discussion of which would find a forum in the journal.

Whereas many of the challenges of 1992 remain just as relevant today, a perusal of the papers in the first issue of Nature Genetics attest to the extraordinary pace of genetic research. Ten years ago, Francis Collins wrote that positional cloning was "genetics in its purest form, unadulterated by any influences of biochemistry, cell biology or physiology". At that time, the genetic etiology of 105 diseases had been described; today there are at least 1,788. In the same issue, Bert Vogelstein and colleagues defined the p53 consensus binding sequence and Craig Venter and colleagues published 106 kilobases of complete human genome sequence and stated, "these results indicate that large parts of the genome can be sequenced using a shotgun approach followed by direct sequencing to fill in the gaps".

To provide a historical record of the past ten years of research, Nature Genetics is pleased to announce the publication, later this year, of a volume of reviews. These will chronicle the development of different areas of genetic research, assess the current state of the field, and highlight challenges of the future. In the meantime, Nature Genetics remains committed to serving the genetic community by providing researchers with "a vehicle for the publication of important research". What will be considered important in the next decade? To some extent, more of the same, although supplemented by insights from even more ambitious undertakings in genomics: gene-gene interactions, genetic contributions to complex disease, and systems biology. Grand questions, indeed.

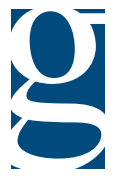

